\title{
Bolt fatigue parametric study of a bolted assembly
}

\author{
Aliou Badara Camara ${ }^{1}$, Fabienne Pennec ${ }^{1}$, Sébastien Durif $^{1}$, Jean-Louis Robert ${ }^{1}$, \\ Abdelhamid Bouchaïr ${ }^{1}$ \\ ${ }^{1}$ Université Clermont Auvergne, CNRS, Institut Pascal, F-63000 Clermont-Ferrand, France
}

\begin{abstract}
Structural integrity of aircraft, nuclear power plants, space rockets, ships, automotive structures, biomedical devices, and many other applications, is a major design purpose and concerns various components subjected to cyclic loads for which fatigue is generally the dominant factor leading to its failure. The fatigue damage cumulation phenomenon is a process which may lead to cracks initiation and possibly to the structure failure under the action of variables stresses cycles. The mechanical components are generally subjected to multiaxial stress states. Taking into account this stress states triaxiality generally deals with multiaxial fatigue criteria. They are suitable tools for assessing the material fatigue resistance against periodical stress states, especially when they are multiaxial. The study carried out in this paper aims to analyze the fatigue behaviour of prestressed bolts involved in a so-called tee-stub bolted assembly that is subjected to variable loads. A multiaxial fatigue post-processing tool using two multiaxial fatigue approaches (integral approach and critical plan approach) is developed and implemented on Matlab software in order to assess the bolt fatigue damage and then its fatigue life through an iterative process. The tool is validated by fatigue test results on bolted assemblies found in the literature, which are additionally compared with those obtained by standards (Eurocode, VDI). A parametric study on the tee-stub is then performed.
\end{abstract}

\section{Introduction}

Metal structures essentially consists of a set of elements such as columns and beams. To ensure the correct transmission of forces between these elements, links are made between components according to different methods as bolting. Bolted assemblies are probably the most widely used mechanical connections. In order to clearly understand the fatigue behaviour of bolted connections, a tee-stub where bolts are submitted to a pretension force is numerically studied by the use of Finite Element Model on Salome-Meca software. Then, a fatigue post-treatment tool is implemented on Matlab software and uses two multiaxial fatigue approaches. It allows to assess the fatigue damage and the fatigue life of material or structures under multiaxial constant amplitude cyclic stress states. Two multiaxial fatigue criteria were implemented; they are related to the so called critical plane approach (Dang Van 
criterion) and to the integral approach (Zenner criterion). Finally, we performed a parametric study to analyze the respective influences upon the bolt fatigue behaviour of the preload, of the bolt location and of the tee-stub thickness.

\section{Finite Element Model of the tee-stub}

3D finite element models have been developed by the use of Salome-Meca software to quantify the axial force $F_{B}$ and the bending moment $M_{B}$ that exists in the bolts throughout the external loading of the tee-stub. These models allow then the calculation of the axial stresses distribution over the cross-section of the bolts shank.

\subsection{Geometry}

One eighth of the tee-stub is modelled by taking into account all the symmetry conditions and the contact zones (as shown on figure 1). This tee-stub model has been parametered thereafter, so that one can easily move from one geometrical configuration to another one. The two geometrical parameters of the tee-stub are the bolt location $\mathrm{m}$ and the column flange thickness $t_{f}$ (figure 2a). Constant amplitude cyclic loading $\mathrm{F}$ is applied upon the tee-stub (figure 1).
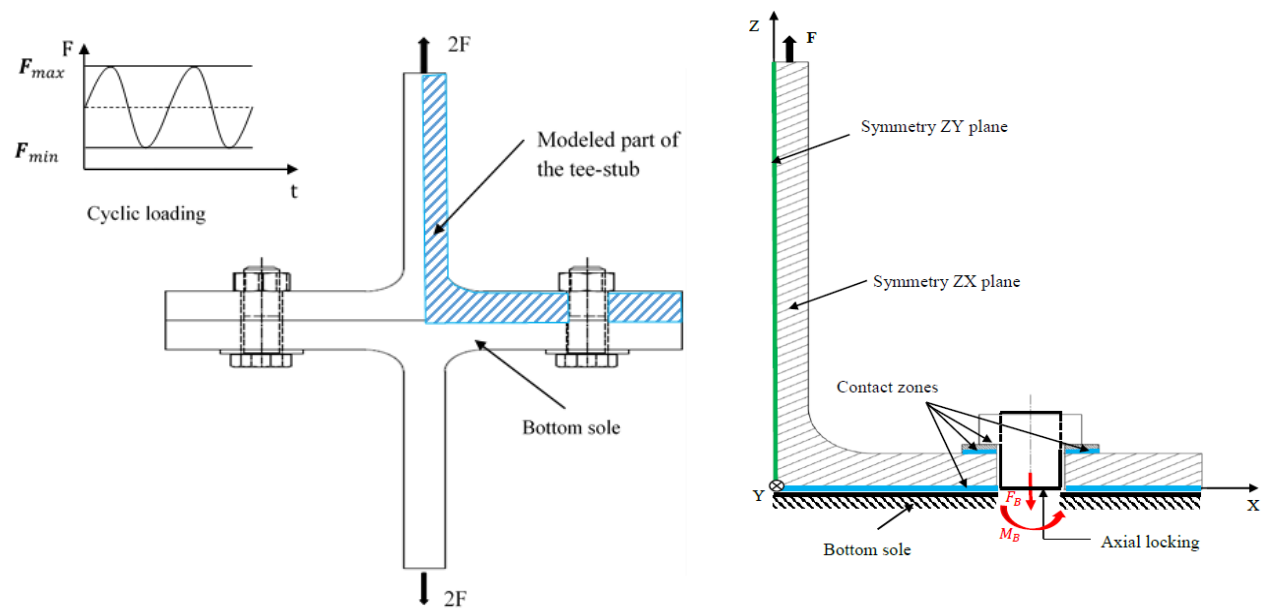

Fig. 1. Description of the tee-stub geometry in $\mathrm{XZ}$ symmetry plane

Once the assessment of the axial load $\left(F_{B}\right)$ and the bending moment $\left(M_{B}\right)$ are realised from the tee-stub model, half the bolt is modelled on Salome-Meca software. This bolt model takes into account the fillet radius $r$ and the first fillet of the shank where it engages in the nut (figure $2 \mathrm{~b}$ ) as previous studies have shown that it holds a large part of the load [1]. Then the axial load $\left(F_{B}\right)$ and the bending moment $\left(M_{B}\right)$ are applied to the bolt as it was in the tee-stub (figure $2 \mathrm{~b}$ ). The goal is to exhibit the multiaxial stress states distribution and to analyse their effect onto the bolt fatigue behaviour. 


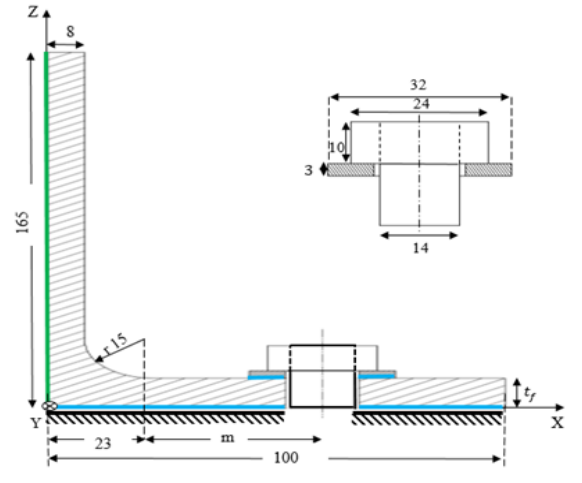

(a)

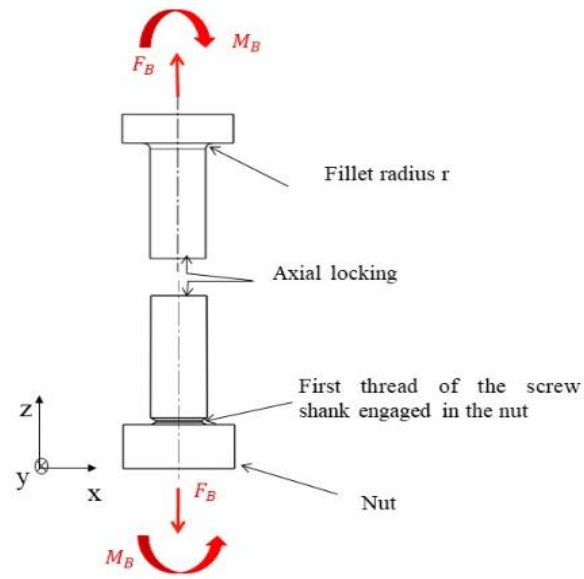

(b)

Fig. 2. a) Geometrical parameters of the tee-stub; b) Bolt model with fillet radius and first thread submitted to the axial force and the bending moment loading

\subsection{Material properties and model mesh}

Materials have a bi-linear elastic-plastic behaviour and the bolt is referred to 8.8 class. Materials mechanical data are given in table 1 .

Table 1. Materials properties

\begin{tabular}{|c|c|c|c|}
\cline { 3 - 4 } \multicolumn{1}{c|}{} & E (GPa) & $v$ & $\sigma_{\mathrm{y}}(\mathrm{MPa})$ \\
\hline Bolt & \multirow{2}{*}{210} & 0.3 & 640 \\
\cline { 1 - 2 } & & & 355 \\
\hline
\end{tabular}

Tetrahedral solid elements are utilized to mesh the numerical models in order to realise their stress-strain response analysis (figure 3 ). The bolt model is refinely meshed with $60 \mu \mathrm{m}$ size tetrahedral elements in the stress concentration zones (first fillet of the shank where it engages in the nut).

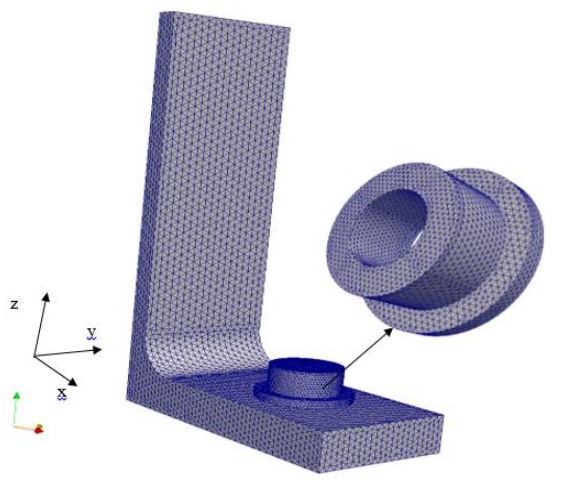

(a)
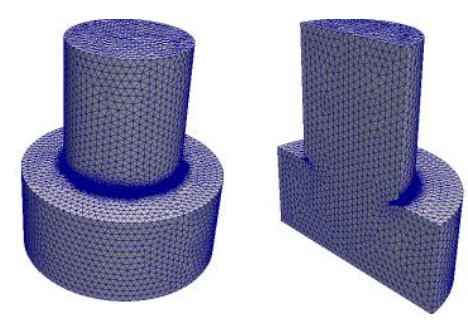

(b) 
Fig. 3. a) Tee-stub mesh ( $\mathrm{m}=40 \mathrm{~mm}$ and $\mathrm{tf}=15 \mathrm{~mm}$ ); b) Mesh of the bolt part taking into account the first thread of the screw shank engaged in the nut

\section{Fatigue analysis tools}

Multiaxial stress states are observed in stress concentration zones. A multiaxial fatigue posttreatment tool is thus implemented on Matlab software in order to analyse the bolt behaviour from the fatigue point of view (figure 4a). The purpose is also to investigate the validity of the so-called critical plane approach (Dang Van criterion) versus the integral approach (Zenner criterion).
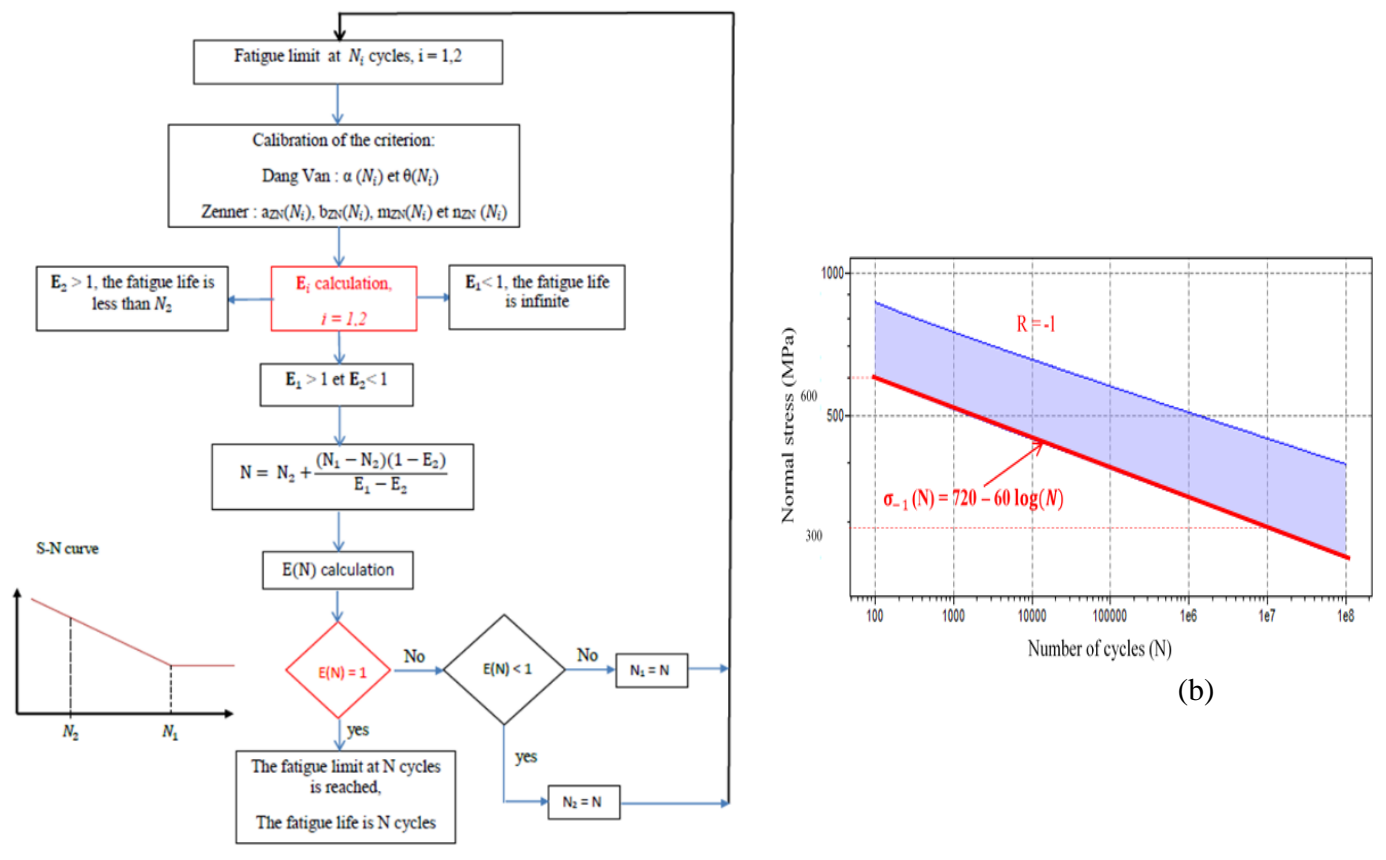

(b)

(a)

Fig. 4. a) Flowchart of the iterative procedure for assessing fatigue life; b) Bolt S-N curve under fully reversed tensile load [from CES edupack 2018]

\subsection{Dang Van criterion}

The Dang Van criterion was the first multiaxial fatigue criterion that was introduced in 1973 in the French industry (by PSA car manufacturer). It was originally presented through considerations established at the microscopic scale, even when the criterion uses timedependent macroscopic stresses which are the alternating part of the shear stress $\tau_{\mathrm{ha}}$ and the hydrostatic pressure $\mathrm{p}$ [2],[3]. The criterion fatigue damage function $\mathrm{E}$ is obtained as the maximization of the damage indicator $\mathrm{E}_{\mathrm{h}}$, defined on the material plane which unit normal vector is $\mathrm{h}$ by:

$$
\mathrm{E}_{\mathrm{h}}=\operatorname{Max}_{t}\left\{\frac{\tau_{\mathrm{ha}}(t)+\alpha \cdot p(\mathrm{t})}{\theta}\right\}
$$


Where $p(t)=\frac{I_{1}(t)}{3}=\frac{\sigma_{11}(t)+\sigma_{22}(t)+\sigma_{33}(t)}{3}$,

$I_{1}(t)$ is the time dependent first invariant of the stress tensor,

$\tau_{\mathrm{ha}}(\mathrm{t})$ is the alternating shear stress acting at time $\mathrm{t}$ on the material plane; it is obtained by determining the smallest circle surrounding to the load trajectory [4].

The plane where $\mathrm{E}_{\mathrm{h}}$ is maximal is the so-called critical plane. It allows the criterion to express the material fatigue damaging effect generated by the multiaxial loading cycle.

The fatigue function of the criterion is thus written as:

$$
\mathrm{E}_{\mathrm{DV}}=\operatorname{Max}_{h}\left(E_{h}\right)
$$

The fatigue function of the criterion is equal to unity when the fatigue limit of the material is reached by the analysed multiaxial stress cycle. This fatigue function $\left(\mathrm{E}_{\mathrm{DV}}\right)$ is also checked for particular material fatigue limits as those related to fully reversed tension fatigue limit $\left(\sigma_{-1}, \mathrm{R}=-1\right)$, fully reversed torsion fatigue limit $\left(\tau_{-1}, \mathrm{R}=-1\right)$. This allows to calibrate the criterion, i.e to determine the two parameters $\alpha$ and $\theta$ that are involved within the $\mathrm{E}_{\mathrm{h}}$ damage indicator formulation:

$$
\left\{\begin{array}{l}
\alpha=3\left(\frac{\tau_{-1}}{\sigma_{-1}}-\frac{1}{2}\right) \\
\theta=\tau_{-1}
\end{array}\right.
$$

One has to notice that Dang Van criterion is valid only when $\frac{\tau_{-1}}{\sigma_{-1}}>\frac{1}{2}$

\subsection{Zenner criterion}

This criterion defines its material plane damage indicator by:

$$
\mathrm{E}_{\mathrm{h}}=\mathrm{a}_{\mathrm{zn}} \tau_{\mathrm{ha}}^{2}\left(1+\mathrm{m}_{\mathrm{zn}} \tau_{\mathrm{hm}}^{2}\right)+\mathrm{b}_{\mathrm{zn}} \sigma_{\mathrm{hha}}^{2}\left(1+\mathrm{n}_{\mathrm{zn}} \sigma_{\mathrm{hhm}}\right)
$$

The criterion formulation provides two terms related to the shear stress $\left(\tau_{\mathrm{ha}}\right.$ and $\left.\tau_{\mathrm{hm}}\right)$ and two others ( $\sigma_{\mathrm{hha}}$ and $\left.\sigma_{\mathrm{hhm}}\right)$ related to the normal stress [4] acting on the plane which unit normal vector is $\mathrm{h}$ :

$\tau_{\mathrm{ha}}$ and $\tau_{\mathrm{hm}}$ are the amplitude and the mean value respectively of the shear stress acting on material plane oriented by h,

$\sigma_{\mathrm{hha}}$ and $\sigma_{\mathrm{hhm}}$ are the amplitude and the mean value of the normal stress acting on the considered plane.

The fatigue function of the criterion is established as a quadratic mean value of the damage indicator $\mathrm{E}_{\mathrm{h}}$ all over the possibly oriented material planes. Practically it gives:

$$
E_{z n}=\frac{1}{\sigma_{-1}} \sqrt{\frac{15}{2 S} \int_{\gamma=0}^{\pi} \int_{\varphi=0}^{\pi} E_{h} d S}
$$

Where $S=2 \pi$ and $d S=\sin \gamma d \varphi d \gamma$

The criterion formulation includes four parameters that are denoted as $a_{\mathrm{zn}}, \mathrm{b}_{\mathrm{zn}}, \mathrm{m}_{\mathrm{zn}}, \mathrm{n}_{\mathrm{zn}}$ and are established from four fatigue limits (fully reversed and repeated tension and torsion fatigue limits: $\sigma_{-1}$ and $\tau_{-1}, \sigma_{0}$ and $\tau_{0}$ ). The repeated torsion fatigue limit $\tau_{0}$ is in fact assessed from the three other fatigue limits according to the following relation [5].

$$
\tau_{0}=\frac{4 \tau_{-1}}{\frac{2 \sigma_{-1}}{\sigma_{0}}+1}
$$

The material parameters obtained by the criterion calibration are given by: 


$$
\begin{gathered}
\mathrm{a}_{\mathrm{zn}}=\frac{1}{5}\left[3\left(\frac{\sigma_{-1}}{\tau_{-1}}\right)^{2}-4\right] ; \mathrm{b}_{\mathrm{zn}}=\frac{1}{5}\left[6-2\left(\frac{\sigma_{-1}}{\tau_{-1}}\right)^{2}\right] ; \mathrm{a}_{\mathrm{zn}} * \mathrm{~m}_{\mathrm{zn}}=\frac{\left(\sigma_{-1}\right)^{2}-\left(\frac{\tau_{0}}{2}\right)^{2}\left(\frac{\sigma_{-1}}{\tau_{-1}}\right)^{2}}{\frac{12}{7}\left(\frac{\tau_{0}}{2}\right)^{4}} ; \\
\mathrm{b}_{\mathrm{zn}} * \mathrm{n}_{\mathrm{zn}}=\frac{\left(\sigma_{-1}\right)^{2}-\left(\frac{\sigma_{0}}{2}\right)^{2}-\frac{4}{21} \mathrm{a}_{\mathrm{zn}} * \mathrm{~m}_{\mathrm{zn}}\left(\frac{\sigma_{0}}{2}\right)^{4}}{\frac{15}{14}\left(\frac{\sigma_{0}}{2}\right)^{3}}
\end{gathered}
$$

\subsection{Bolt material S-N curves}

As the bolt material S-N curves are not precisely known, some fatigue data are taken from the literature (as CES edupack 2018) to analyze the influence of some parameters on the fatigue behaviour of the tee-stub bolts. The considered S-N curve (figure $4 \mathrm{~b}$ ) derives from the Wöhler model and gives the fatigue lifetime $\mathrm{N}$ under fully reversed tensile load $(\mathrm{R}=-1)$ by:

$$
\sigma_{-1}(\mathrm{~N})=720-60 \log (\mathrm{N})
$$

The material is the AISI 4037 alloy steel which can be used for heavy duty shafts, connecting rods and also high tensile bolts. The other S-N curves (fully reversed torsion load $\mathbf{\tau}_{-1}$, repeated tension $\boldsymbol{\sigma}_{0}$ and torsion $\mathbf{\tau}_{0}$ ) that are necessary for the criteria calibration are derived from this $\mathrm{S}-\mathrm{N}$ curve according to the following assumptions:

- $\frac{\sigma_{-1}(N)}{\tau_{-1}(N)}=\sqrt{3}$, according to Harald Zenner and al. [5], this ratio can vary within the range from 1.25 to 2 for ductile materials,

- $\frac{\sigma_{0}(N)}{\sigma_{-1}(N)}=\sqrt{3}$,

- $\tau_{0}(\mathrm{~N})=\frac{4 \tau_{-1}(\mathrm{~N})}{\frac{2 \sigma_{-1}(\mathrm{~N})}{\sigma_{0}(\mathrm{~N})}+1}$ according to Zenner and al. [5].

\section{Results analysis}

The multiaxial post-treatment tool validation is done with a 8.8 class M10 bolt in $42 \mathrm{CrMo} 4$ for $50 \% \sigma_{\mathrm{y}}$ preload. Indeed fatigue test results for this bolt exist in the literature [6]. The results of the simulation are indeed very close to fatigue tests results. The predictions obtained with Zenner's integral approach are much closer to the experimental results than predictions made by Dang Van's critical plan approach (fig.5.).

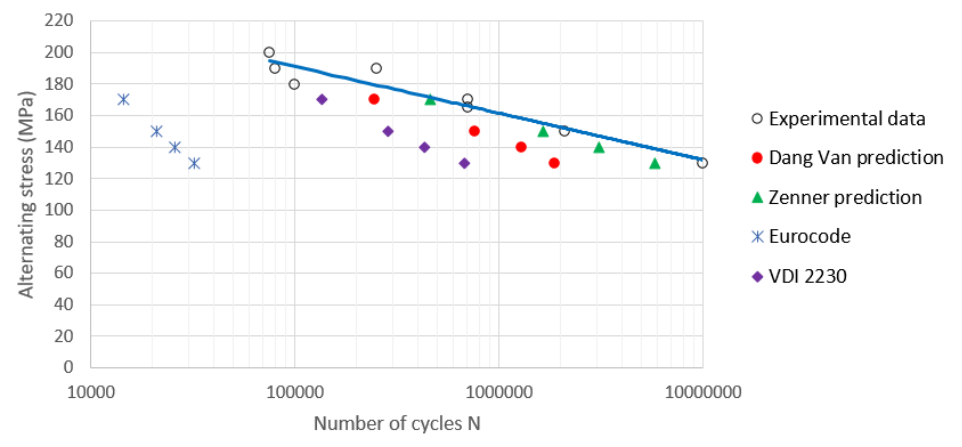


Fig. 5. Fatigue life given by standards and by multiaxial fatigue criteria for M10 bolts 8.8 in 42 CrMo4 with special bolts for a $50 \% \sigma_{\mathrm{y}}$ preload

From the comparison of experimental and numerical lifetimes, it can be stated that the iterative multiaxial fatigue life calculation procedure that we have implemented allows a fairly good prediction of fatigue life when the stress states are fairly calculated and the fatigue properties of the material well identified. It should be noted that the simplified life calculation methods proposed in the standards are not always efficient especially when the stress states are multiaxial, which generally occurs the case for structures in service (railway, aeronautical, automobile etc.). Fig.5. shows the lifetimes obtained by the Eurocode and VDI 2230 standards compared to the predictions obtained with the multiaxial fatigue criteria on the one hand and the test results on the other hand. The lifetimes obtained with the two standards quoted above are different from the test results because they do not take into account the multiaxiality of the stress states.

\subsection{Influence of the bolt location $\mathrm{m}$}

The calculations are carried out for a tee-stub thickness equal to $15 \mathrm{~mm}$ and for some $20 \mathrm{kN}$ preload in the bolts. The fatigue damage and lifetime are assessed for a bolt location equal to $20 \mathrm{~mm}$ and the two used fatigue criteria. The fatigue damage is calculated in any node of the bolt. For each studied case, the maximum value of the fatigue damage is obtained at the first thread of the screw where it engages in the nut (fig.2b). It is thus the critical area of the bolts from the fatigue point of view. Then, we progressively make increase the value of the bolt location, all other parameters remaining equal, in order to analyze the influence of this parameter upon the bolt damage (fig. 6a). It can be seen that the increase of the bolt location strongly emphasize the bolt fatigue damage. From $20 \mathrm{~mm}$ to $40 \mathrm{~mm}$ of the bolt location, the fatigue function is multiplied by 1.25 for Dang Van criterion and by 2.3 for Zenner criterion. These factors are respectively 2.8 and 7.9 for the two criteria when the bolt location varies from $20 \mathrm{~mm}$ to $50 \mathrm{~mm}$.

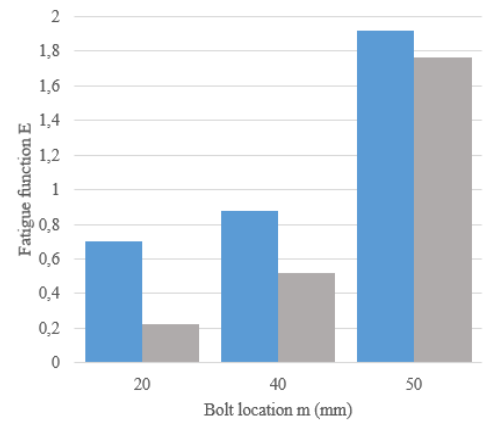

(a)

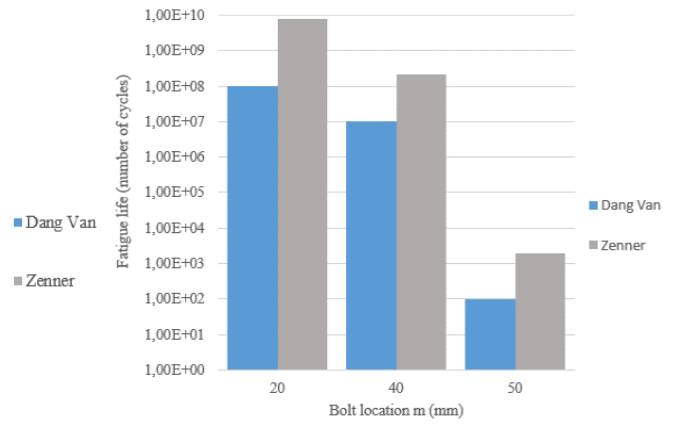

(b)

Fig. 6. a) Bolt fatigue damage function versus bolt location; b) Evolution of the bolt fatigue life versus its location

The factor increases strongly in the fatigue lives domain. As the fatigue damage is inversely proportional to the fatigue life, the huge increase of fatigue damage in the bolt results in a strong decrease of its fatigue life (fig. 6b). The results thus show that the increase of the bolt location is detrimental to its fatigue resistance. 
For a bolt location equal to $40 \mathrm{~mm}$ and for $20 \mathrm{kN}$ preload in the bolts, three different thicknesses (ranging from the initial one to its twofold value) were studied. For each configuration, the damage function $\mathrm{E}$ and its fatigue life $\mathrm{N}$ are calculated by using the multiaxial fatigue post-treatment tool that we implemented on Matlab software. The results obtained are also presented under comparative histograms (fig. 7.).

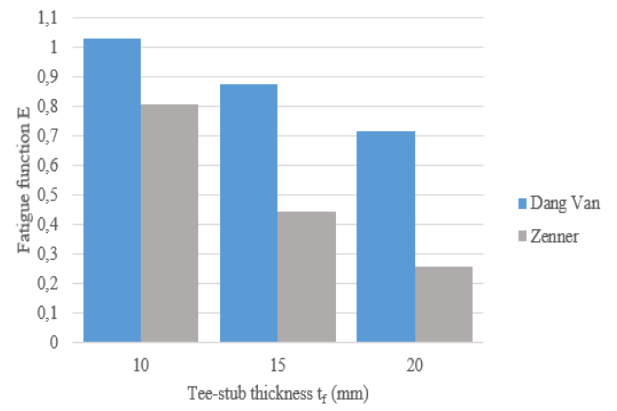

(a)

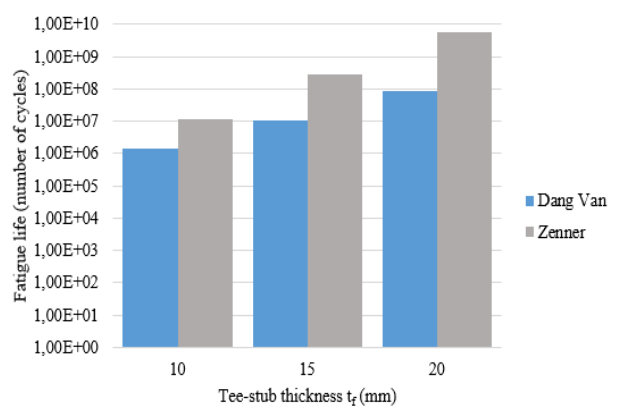

(b)

Fig. 7. a) Sensitivity of bolt fatigue function versus tee-stub thickness; b) Bolt fatigue life as a function of the tee-stub thickness

Both criteria show a beneficial effect of the tee-stub thickness increase upon the fatigue damage of the bolts. This is obviously logical as the increase of the tee-stub thickness stiffens it and then reduces the stresses to which the bolts are subjected. Practically, a small deviation of the fatigue function results in a significant evolution of the fatigue lifetimes. We also observe, according to the results obtained, that Dang Van criterion much more conservative than Zenner one for this application $\left(\mathrm{E}_{\mathrm{ZN}} \leq \mathrm{E}_{\mathrm{DV}}\right.$ and $\left.\mathrm{N}_{\mathrm{ZN}} \geq \mathrm{N}_{\mathrm{DV}}\right)$.

\section{Conclusion}

In this work, we set up on the one hand a fatigue post-treatment tool using two multiaxial fatigue approaches and a numerical model of a tee-tub assembly in which the bolt is finely meshed on the other hand. It is shown that the fatigue life calculation methods proposed by the standards, particularly the Eurocode, are not often adapted to multiaxial fatigue, therefore the multiaxial fatigue criteria remain up to now the approach leading to fatigue life close to the reality both in uniaxial and multiaxial fatigue. However the stress states have to be well determined and fatigue characteristics of the material well identified. The parametric analysis on the tee-stub shows that increasing the column flange thickness $t_{f}$ is beneficial for the fatigue behaviour of the bolt in a tee-stub type assembly whereas the bolt location increase has a detrimental influence on it. A small deviation of the fatigue function E results in a significant change of the fatigue lifetimes N. Additionally, Dang Van criterion is more conservative for this application than Zenner criterion.

\section{Reference}

1. M. Tanaka, K. Hongo, Stress analysis of threaded connections by Finite Element Method JSM, 1454-1461 (1981)

2. K. Dang Van, A. Le Douaron, H.P, Lieurade, Multiaxial fatigue limit: a new approach, 1879-1885 (1984) 
3. K. Dang Van, O. Griveau, B. Message, On a new Multiaxial fatigue limite criterion : Theory and application, 479-496 (1989)

4. B. Weber, B. Kenmeugne, J.C. Clement, J.L. Robert, Improvements of multiaxial fatigue criteria computation for a strong reduction of calculation duration, Elsevier 15,381-399 (1999)

5. J. Liu, H. Zenner, Berechnung der Dauerschwingfestigkeit bei mehrachsiger Beanspruchung-Teil1, Mat- wiss 24, 240-247 (1993)

6. J. Guillot, Modélisation et calcul des assemblages vissés, Tech. Ing, 8-11 (2007) 